\title{
GAMBARAN SANITASI J AMBAN DI SEKOLAH DASAR NEGERI DI WILAYAH KECAMATAN KIKIM TIMUR TAHUN 2016
}

\author{
Ulfah \\ Program Studi Kesehatan Masyarakat STIK Bina Husada Palembang \\ Email: ulfah.maria449@gmail.com
}

\begin{abstract}
One of the guidance and development of healthy schools is through the guidance and assessment on the physical environment of the school, as many as 145 thousand Jamban in elementary schools all over Indonesia is not hygienic, the condition of Poor toilet and less attention becomes the reason Jamban is a means of disease for children in elementary school.

This research method is descriptive quantitative. The data obtained were univariatally analyzed. This research was conducted in 27 public elementary schools located in East Kikim District conducted with observation to see sanitation of toilets at public elementary school in East Kikim sub-district in November 2016.

The results showed that of the 27 Elementary School in District Area Kikim East, primary schools have latrines qualify as many as 10 elementary schools and do not qualify requirements as much as 17 primary schools, primary schools which have a source of clean water that qualifies as many as 12 schools basic and unqualified 15 elementary schools, have eligible Septic Tank 8 primary schools and do not meet the requirements of 19 primary and elementary schools that have eligible wastewater disposal for 9 primary schools and do not meet 18 primary schools.

The conclusion of this study is that there are 27 elementary schools in East Kikim Sub-district with eligible Jamban for 10 elementary schools, elementary school with eligible water source of 12 elementary schools, has Septic Tank qualified 8 elementary and elementary school which has eligible waste disposal of 9 primary schools.
\end{abstract}

\section{Keywords: Sanitation, Toilet, Elementary School}

\section{ABSTRAK}

Salah satu pembinaan dan pengembangan sekolah sehat adalah melalui pembinaan dan penilaian pada keadaan lingkungan fisik sekolah, sebanyak 145 ribu Jamban di sekolah dasar seluruh Indonesia tidak hygienis, kondisi Jamban yang seadanya dan kurang perhatian menjadi alasan Jamban adalah sarana penyakit bagi anak-anak di sekolah dasar. 
Metode penelitian ini adalah deskriptif kuantitatif. Data yang diperoleh dianalisa secara univariat. Penelitian ini dilakukan di 27 Sekolah Dasar Negeri yang ada di Kecamatan Kikim Timur yang dilakukan dengan observasi untuk melihat sanitasi Jamban di Sekolah Dasar Negeri di Kecamatan Kikim Timur pada Bulan November 2016.

Hasil penelitian menunjukkan bahwa dari 27 Sekolah Dasar Negeri di Wilayah Kecamatan Kikim Timur, sekolah dasar yang memiliki jamban yang memenuhi syarat sebanyak 10 sekolah dasar dan tidak memenuhi syarat syarat sebanyak 17 sekolah dasar, sekolah dasar yang memiliki sumber air bersih yang memenuhi syarat sebanyak 12 sekolah dasar dan tidak memenuhi syarat 15 sekolah dasar, memiliki Septic Tank memenuhi syarat ada 8 sekolah dasar dan tidak memenuhi syarat 19 sekolah dasar serta sekolah dasar yang memilki pembuangan air limbah yang memenuhi syarat sebanyak 9 sekolah dasar dan tidak memenuhi 18 sekolah dasar.

Kesimpulan dari penelitian ini bahwa ada 27 sekolah dasar di Kecamatan Kikim Timur yang memiliki Jamban yang memenuhi syarat sebanyak 10 sekolah dasar, sekolah dasar yang memiliki sumber air bersih yang memenuhi syarat sebanyak 12 sekolah dasar, memilki Septic Tank memenuhi syarat 8 sekolah dasar dan sekolah dasar yang memiliki pembuangan air limbah yang memenuhi syarat sebanyak 9 sekolah dasar.

\section{Kata Kunci: Sanitasi, J amban, Sekolah Dasar}

\section{PENDAHULUAN}

Sekolah merupakan

perpanjangan tangan keluarga, artinya sekolah merupakan tempat lanjutan untuk meletakkan dasar perilaku bagi anak, termasuk perilaku kesehatan. Peran guru dalam promosi kesehatan di sekolah sangat penting, karena guru pada umumnya lebih dipatuhi oleh anak-anak daripada orang tuanya. Sekolah dan lingkungan sekolah yang sehat sangat kondusif untuk berperilaku sehat bagi anak-anak. Agar guru dan lingkungan sekolah tersebut kondusif bagi perilaku sehat bagi murid-muridnya, maka sasaran antara promosi kesehatan di sekolah adalah guru

(Notoatmodjo, 2010).

Salah satu pembinaan dan pengembangan sekolah sehat adalah melalui pembinaan dan penilaian pada keadaan lingkungan fisik sekolah, peserta didik dan tenaga pendidikan, serta pada berbagai kegiatan. Organisasi serta pengaruh timbal balik sekolah dan masyarakat sekitar dalam rangka mencapai tujuan pendidikan secara optimal (Santoso, 2015).

Sebanyak 145 ribu toilet di sekolah dasar seluruh Indonesia tidak hygienis, kondisi toilet yang seadanya dan kurang perhatian menjadi alasan toilet sebagai sarana penyakit bagi anak-anak di 
sekolah dasar (Puspaningtyas dkk, 2016). Menurut penelitian Afriana (2012), disimpulkan jamban yang memenuhi syarat 1

\section{METODE}

Metode penelitian ini adalah deskriptif kuantitatif, yaitu suatu metode penelitian yang dilakukan dengan tujuan utama untuk membuat gambaran atau deskripsi tentang suatu keadaan secara objektif (Notoatmodjo, 2012). Data yang diperoleh dianalisa secara univariat untuk mendeskripsikan karakteristik masing-masing variabel yang di teliti. Penelitian ini dilakukan di 27 sekolah dasar negeri yang ada di Wilayah Kecamatan Kikim Timur. Data primer dilakukan dengan melakukan observasi untuk melihat hygiene sanitasi kamar mandi di Sekolah Dasar Negeri di Kecamatan Kikim Timur. Data sekolah $(8,3 \%)$ dan yang tidak memenuhi syarat 11 sekolah $(91,7 \%)$.

sekunder di peroleh dari dokumen dan arsip-arsip sekolah. Populasi dalam penelitian ini adalah 27 sekolah dasar negeri yang ada di wilayah Kecamatan Kikim Timur. Sampel pada penelitian ini adalah total populasi yaitu 27 Sekolah Dasar Negeri yang ada di Wilayah Kecamatan Kikim Timur.

\section{HASIL}

Dari Hasil analisis univariat, diperoleh gambaran sanitasi Jamban berdasarkan variabelvariabel penelitian, sehingga analisis ini dapat dilihat pada Tabel 1 dan Diagram 1 berikut ini. 
Tabel. 1

Hasil Analisis Univariat (Variabel J amban, Sumber Air Bersih, Septic Tank, Pembuangan Air Limbah)

\begin{tabular}{lcc}
\hline \multicolumn{1}{c}{ Variabel } & N & \% \\
\hline J amban & 10 & 37 \\
- Ada dan memenuhi syarat & 17 & 63 \\
- Ada tapi tidak memenuhi syarat & & \\
Sumber Air B ersih & 12 & 44,5 \\
- Ada dan memenuhi syarat & 15 & 55,5 \\
$\quad$ - Ada tapi tidak memenuhi syarat & 8 & 29,6 \\
Septic Tank & 19 & 70,4 \\
- Ada dan memenuhi syarat & & \\
- Ada tapi tidak memenuhi syarat & 9 & 33,3 \\
Pembuangan Air Limbah & 18 & 66,7 \\
$\quad$ - Ada dan memenuhi syarat &
\end{tabular}

Hasil uji univariat diatas bahwa untuk variabel Jamban di 27 Sekolah Dasar negeri dipeoleh 10 Sekolah Dasar Negeri (37\%) yang memiliki Jamban memenuhi syarat sedangklan 17 sekolah lainya (63\%) memiliki Jamban yang tidak memenuhi syarat.

Untuk variabel Sumber Air Bersih pada hasil analisis univariat diperoleh dari 27 Sekolah Dasar Negeri terdapat 12 Sekolah Dasar Negeri (44,5\%) yang sumber air bersihnya memenuhi syarat sedangkan 15 Sekolah Dasar Negeri lainnya $(55,5 \%)$ mempunyai sumber air bersih yang tidak memenuhi syarat.

Selanjutnya untuk variabel Septic Tank pada hasil analisis univariat diperoleh bahwa dari 27 sekolah dasar terdapat 8 sekolah dasar $(29,6 \%)$ yang memenuhi syarat sedangkan 19 sekolah dasar lainnya $(70,4 \%)$ mempunya Septic Tank yang tidak memenuhi syarat.

Sedangkan untuk variabel Pembuangan Air Limbah dari hasil analisis univariat diatas memperoleh bahwa dari 27 Sekolah Dasar Negeri terdapat 9 Sekolah Dasar Negeri (33,3\%) yang pembuangan air limbahnya memenuhi syarat dan 18 Sekolah Dasar Negeri yang pembuangan air limbahnya tidak memenuhi syarat $(66,7 \%)$.

\section{PEMBAHASAN}

Persoalan sanitasi dasar merupakan permasalahan utama yang dihadapi hampir sekolah yang ada di Wilayah Kecamatan Kikim Timur. Hasil penelitian menunjukkan sebanyak $63 \%$ 
sekolah status sanitasi Jamban tergolong buruk. Kondisi ini terjadi karena tidak didukung oleh sarana yang cukup. Jamban yang tidak memenuhi, penyediaan sumber air bersih tidak memenuhi syarat kesehatan, ketersediaan Septic Tank yang tidak memadai dan pembuangan air limbah yang tidak baik.

Penelitian ini sejalan dengan Notoatmodjo (2007) yang menyatakan bahwa Jamban memiliki persyaratan-persyaratan yang harus dipenuhi, maka perlu memperhatikan bangunan Jamban terlindung dari panas dan hujan, serangga dan binatang-binatang lain, terlindung dari pandangan orang, memiliki lantai yang kuat dan memiliki saluran pembuangan limbah serta memiliki penampungan supaya tidak menimbulkan bau dan sedapat mungkin disediakan air bersih.

Hal ini sesuai dengan pendapat Chandra (2006) air yang diperuntukkan bagi konsumsi manusia harus berasal dari sumber yang bersih dan aman, antara lain bebas dari kontaminasi kuman atau bibit penyakit, bebas dari substansi kimia yang berbahaya dan beracun, tidak terasa dan berbau, dapat dipergunakan untuk mencukupi kebutuhan domestik dan rumah tangga serta memenuhi standar minimal yang di tentukan oleh WHO atau Depkes RI.

Berdasarkan observasi langsung di lapangan ternyata faktor yang paling dominan dapat menyebabkan fasilitas sanitasi dasar yang ada tidak terpelihara dengan baik dikarenakan belum adanya petugas kebersihan di setiap sekolah, rumah penjaga dan rumah Kepala Sekolah tidak dihuni, sekolah tidak mempunyai mesin pompa air guna mengalirkan air dari sumber air bersih ke bak-bak di kamar mandi serta kurangnya partisipasi Kepala Sekolah dan Guru dalam mengarahkan anak didiknya dalam hal pemeliharaan fasilitas sanitasi dasar yang ada di Sekolah.

\section{KESIMPULAN}

a. Dari 27 Sekolah Dasar Negeri di Wilayah Kecamatan Kikim Timur ada 10 (37,7\%) sekolah dasar yang Jambannya memenuhi syarat dan ada 17 $(63 \%)$ yang tidak memenuhi syarat.

b. Dari 27 Sekolah Dasar Negeri di Wilayah Kecamatan Kikim Timur ada 12 (44,5\%) sekolah dasar yang sumber air bersihnya memenuhi syarat dan ada 15 (55,5\%) sekolah dasar yang tidak memenuhi syarat.

c. Dari 27 Sekolah Dasar Negeri di Wilayah Kecamatan Kikim 
Timur ada $8 \quad(29,6 \%)$ yang memiliki Septic Tank memenuhi syarat dan ada 19 sekolah dasar $(70,4 \%)$ tidak memenuhi syarat.

d. Dari 27 Sekolah Dasar Negeri di Wilayah Kecamatan Kikim Timur yang memiliki pembuangan air limbah yang memenuhi syarat 9 sekolah dasar $(33,3 \%)$ sedangkan yang tidak memenuhi syarat 18 sekolah dasar $(66,7)$.

SARAN

a. Sekolah Dasar Negeri di Wilayah Kecamatan Kikim Timur

- Diperlukan upaya peningkatan pemahaman tentang program kesehatan lingkungan bagi seluruh pendidik (guru) di Wilayah Kecamatan Kikim Timur Kabupaten Lahat yaitu dengan melalui pertemuan terjadwal (lintas sektoral) dalam rangka pembekalan tentang pentingnya melaksanakan program kesehatan lingkungan pada institusi pendidikan.

- Disarankan kepada pihak institusi pendidikan untuk selalu mengajarkan dan mengawasi para siswanya agar sedini mungkin membiasakan memelihara kebersihan

sarana

kesehatan yang ada.

b. Peneliti

Memberikan kesempatan yang lebih luas untuk mengembangkan pendidikan sesuai dengan minat dan bidang yang dikuasai.

\section{DAFTAR PUSTAKA}

Afriana, Lensi., 2012. Analisis Sekolah Sehat di Wilayah Kerja Puskesmas Sungai dua Kecamatan Rambutan Kabupaten Banyuasin. Skripsi. Palembang: STIK Bina Husada.

Chandra, Budiman., 2006. Pengantar Kesehatan Lingkungan. Jakarta: EGC.

Kemenkes RI., 2013. ROAD MAP Percepatan Program STBM (Strategi Nasional Sanitasi Total Berbasis Masyarakat). J urnal Kesehatan. Diakses 4 Januari 2016.

Notoatmodjo, Soekidjo., 2007. Kesehatan Masyarakat: IImu dan Seni. Jakarta: Rineka Cipta.

Notoatmodjo, Soekidjo., 2010. Promosi Kesehatan Teori dan Aplikasi. Jakarta: Rineka Cipta.

Notoatmodjo., Soekidjo., 2012. Metode Penelitian Kesehatan, Jakarta: Rineka Cipta.

Lawrence N W., 2013. Metode Penelitian Sosial: 
Pendekatan Kualitatif dan Kuantitatif. Cetakan Pertama. Jakarta: PT. Indeks.

Puspaningtyas, Lida Muftisany Hafidz., 2012. Miris, 145 Ribu Toilet Se Indonesia
Tak Hygienis. Tabloid Republika. Diakses 5 Januari 2016.

Santoso, Imam., 2015. Inspeksi Sanitasi Tempat-Tempat Umum. Yogyakarta: Gosyen Publishing. 